
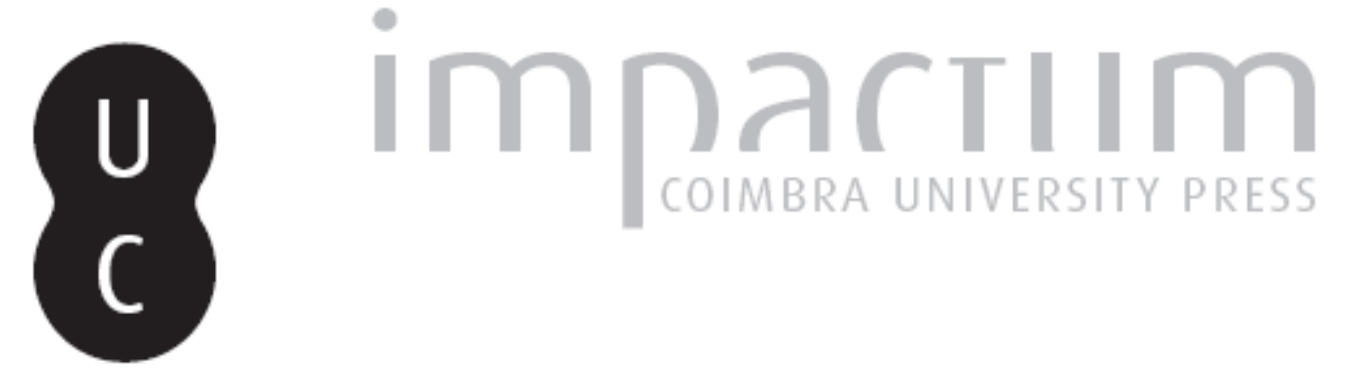

\title{
[Recensão a] LIN FOXHALL, Studying Gender in Classical Antiquity
}

\author{
Autor(es): $\quad$ Rodrigues, Nuno Simões
}

Publicado por: Centro de História da Universidade de Lisboa

URL persistente:

URl:http://hdl.handle.net/10316.2/35016

DOI:

DOI:http://dx.doi.org/10.14195/0871-9527_23_24

Accessed : $\quad$ 26-Apr-2023 13:41:33

A navegação consulta e descarregamento dos títulos inseridos nas Bibliotecas Digitais UC Digitalis, UC Pombalina e UC Impactum, pressupõem a aceitação plena e sem reservas dos Termos e Condições de Uso destas Bibliotecas Digitais, disponíveis em https://digitalis.uc.pt/pt-pt/termos.

Conforme exposto nos referidos Termos e Condições de Uso, o descarregamento de títulos de acesso restrito requer uma licença válida de autorização devendo o utilizador aceder ao(s) documento(s) a partir de um endereço de IP da instituição detentora da supramencionada licença.

Ao utilizador é apenas permitido o descarregamento para uso pessoal, pelo que o emprego do(s) título(s) descarregado(s) para outro fim, designadamente comercial, carece de autorização do respetivo autor ou editor da obra.

Na medida em que todas as obras da UC Digitalis se encontram protegidas pelo Código do Direito de Autor e Direitos Conexos e demais legislação aplicável, toda a cópia, parcial ou total, deste documento, nos casos em que é legalmente admitida, deverá conter ou fazer-se acompanhar por este aviso.

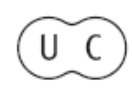



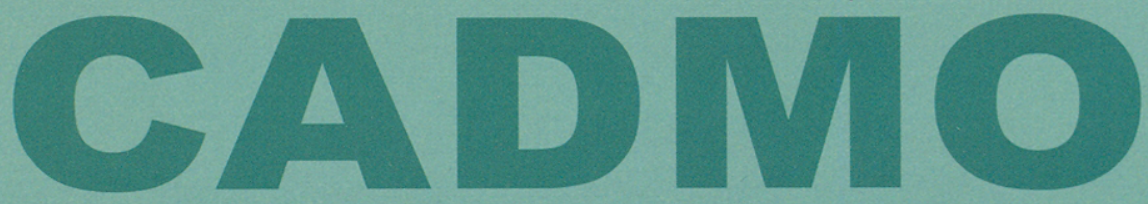

Revista de História Antiga

\author{
Centro de História \\ da Universidade de Lisboa
}

\title{
23
}

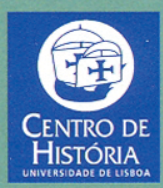

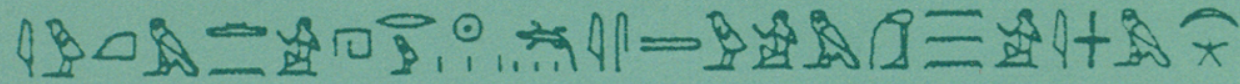

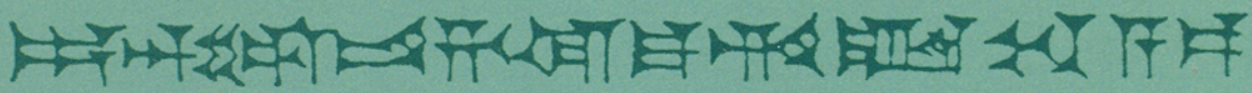
MHNIN AEI $\triangle \mathrm{E} \Theta \mathrm{EA}$ ПH$\Lambda \mathrm{HIA} \triangle \mathrm{E} \Omega$ 
estudos publicado há anos pelo Centro de Estudos Clássicos da Universidade de Lisboa, sobre Eros e Philia.

\section{Nuno Simões Rodrigues}

LIN FOXHALL, Studying Gender in Classical Antiquity, Cambridge: Cambridge University Press, 2013, 188 pp. ISBN 978-0-521-55739-9 (£18.99, US\$29.99).

Integrado de forma pertinente na colecção «Key Themes in Ancient History", este livro de L. Foxhall merece todo o destaque por funcionar como sebenta de introdução a um tema que tem despertado o maior interesse de historiadores e de outros investigadores das ciências sociais e humanas. Para o estudo da Antiguidade Clássica, o processo parece ter sido exactamente o mesmo que para o de outras épocas históricas, como se deduz das palavras da A.: "Once upon a time the history of the ancient classical world was primarily the story of great men and their battles.» (p. 1). Mas as novas leituras e correntes historiográficas acabaram por influenciar também as perspectivas nesta nossa área do saber e esse processo acabou por se reflectir na produção académica daí decorrente.

O livro de Foxhall é exemplo dessas novas abordagens. Nele, a A. destaca a pluralidade de percepções no que diz respeito ao género e a forma como essas diferenças se reflectiram nas sociedades grega e romana. Mais, Foxhall destaca a forma como as leituras e interpretações do género, longe de serem uma realidade sócio-cultural isolada, teve consequências determinantes no modo como o mundo greco-romano se organizou e estruturou, estando assim relacionadas de forma inequívoca com todos os quadrantes da sociedade, do político ao cultural e mental.

Assim, depois de uma breve mas útil resenha bibliográfica que funciona também como introdução (pp. 1-23), e em que Foxhall sintetiza as etapas do processo de emancipação desta "disciplina» no âmbito dos Estudos da Antiguidade Clássica, podemos encontrar neste livro o tratamento, em estilo de introdução segundo a perspectiva dos Estudos de Género, das várias áreas em que é possível percebermos a pertinência do tema em análise.

São sobretudo seis, as áreas aqui tratadas pela A. A primeira delas, o lar ou o agregado familiar (household, pp. 24-44) aborda os problemas da organização da casa/lar e da família, do papel do homem e da mulher (visto que aqui também se evidencia a necessidade, pertinente, de frisar que a história do género não é uma disciplina especialmente vocacionada para o estudo das mulheres - como por vezes se assume de forma equívoca - mas 
sim para os géneros!) no oikos grego e na domus romana. Neste âmbito, é igualmente importante avaliar o papel do casamento na organização social, bem como aquilo que é esperado de cada um dos géneros envolvidos. Revela-se assim igualmente pertinente a análise dos elementos desestruturantes do casamento, designadamente o adultério, bem como das formas em que este contribui para a desordem social.

Em relação à demografia (pp. 45-67), problematizam-se os números associados aos movimentos e variações populacionais, consoante os géneros, relacionando estes com a cronologia, a geografia (Grécia e Roma) e as idades, mas também os tempos da vida (infância, idade adulta e velhice). Também a morte faz parte do universo demográfico e por isso é incluída nesta análise.

No que diz respeito ao corpo (pp. 68-89), tratam-se as «naturais» problemáticas da saúde a ele associadas, em particular as formas de a entender, percepcionar e «resolver» (e. g. textos médicos produzidos na Antiguidade Clássica) de acordo com o género a que se pertence, mas também as interpretações somáticas, designadamente ao nível da arte e das formas plásticas de representar a matéria corpórea humana. Nesta rubrica, ganha particular dimensão a problemática do nu que, como se sabe, é central nas definições da escultura greco-romana, dadas as implicações sócio-culturais que lhe são subjacentes. As variações na representação do nu ao nível do género são, aliás, parte fundamental nos estudos da história da arte clássica.

Associada à economia e à sociedade, a riqueza (pp. 90-113) tem também um lugar especial nesta introdução. Os problemas da propriedade, da herança, do direito, do trabalho e das formas do exercer (e.g. prostituição) devem ser articuladas com as problemáticas do género, visto que socialmente variam de acordo com os agentes neles envolvidos. Consideramos mesmo este um capítulo fundamental no livro de Foxhall, uma vez que nele se trata do domínio que, eventualmente, terá angariado a consagração científica para os estudos de género no âmbito da história.

Há ainda lugar para dois capítulos ligados ao espaço e à religião. Em relação ao primeiro (pp. 114-136), a A. aborda sobretudo as questões associadas ao espaço público e ao espaço privado e as formas como elas se manifestam em problemáticas mais alargadas, da organização social ao urbanismo. No que diz respeito à religião (pp. 137-157), é inquestionável que esta se revelou e manifestou na Antiguidade Clássica com recurso a uma organização que não raramente se definiu pelo género dos seus intervenientes: sacerdócios, cultos, ritos, tradições mitológicas, superstição, magia, todos estes são aspectos em que ser homem ou ser mulher, pertencer ao universo do masculino ou ao do feminino não é um mero acessório marginal, mas parte fundamental da questão. 
Seguindo este fio condutor, L. Foxhall oferece assim aos estudantes da Antiguidade modelos de análise e traz à colação problemas hoje tidos como fundamentais na organização das sociedades ditas clássicas. Do livro faz ainda parte uma bibliografia actualizada (que inclui um pequeno ensaio com comentário bibliográfico), bem como um índice temático. Teria sido útil uma lista de fontes, sobretudo textos, em que se elencassem os materiais disponíveis para este tipo de estudos. Mas a existir, talvez o livro deixasse de ser aquela breve introdução a «temas chave» que pretende ser. Talvez assim se justifique mesmo uma outra publicação, agora com esses conteúdos.

\section{Nuno Simões Rodrigues}

SHARON L. JAMES AND SHEILA DILLON, eds., A Companion to Women in the Ancient World. Blackwell Companions to the Ancient World, Oxford: Blackwell Publishing Ltd., 2012, 616 pp. ISBN 978-1-4051-9284-2.

Cremos não ser exagerado afirmar que com este livro estamos perante mais um exemplo de competência científica e eficácia académica e pedagógica. Com efeito, este "Companion to Women» é um exemplo perfeito de um trabalho bem estruturado e de uma síntese prática e eficiente do que se espera de um volume de tipo "sebenta académica», cujo objectivo é transmitir o «estado da arte» da área a que é dedicado, para estudantes e investigadores de vários níveis e plataformas de trabalho.

Incluído na já famosa colecção da «Blackwell Companions to the Ancient World", este volume dedicado às mulheres do Mundo Antigo prima pelo rigor e pela abrangência da informação. Partindo do foco/centro que são Atenas e Roma na Antiguidade, as organizadoras do volume optaram por estruturá-lo em cinco partes, que se distribuem tendo os tais centros como referência.

Assim, a primeira parte é dedicada às «Women Outside Athens and Rome» (pp. 5-78), apresentando-se textos acerca das mulheres na Pré-História (de que se destaca o importantíssimo tema das deusas-mãe), na Mesopotâmia, no Antigo Egipto, nas sociedades minóica e micénica, nos Poemas Homéricos e entre os Etruscos. De certo modo, podemos afirmar que nesta parte estamos perante o tema da mulher no mundo pré-clássico, latu sensu.

A segunda parte, «The Archaic and Classical Periods» (pp. 79-228), trata de vários aspectos ligados à sociedade grega e da forma como as mulheres intervieram neles ou foram determinantes, ou não, para a sua definição como tais. Assim, podemos ler textos acerca das mulheres e a cidade-estado, o direito, a medicina, a vida quotidiana, as representações artísticas, o vestuário 